University of South Carolina

Scholar Commons

1998

\title{
Characterization of Hydrogen Permeation Through Zinc-Nickel Alloys under Corroding Conditions: Mathematical Model and Experimental Study
}

\author{
M. Ramasubramanian \\ University of South Carolina - Columbia \\ Branko N. Popov \\ University of South Carolina - Columbia, popov@engr.sc.edu \\ Ralph E. White \\ University of South Carolina - Columbia, white@cec.sc.edu
}

Follow this and additional works at: https://scholarcommons.sc.edu/eche_facpub

Part of the Chemical Engineering Commons

\section{Publication Info}

Journal of the Electrochemical Society, 1998, pages 1907-1913.

(c) The Electrochemical Society, Inc. 1998. All rights reserved. Except as provided under U.S. copyright law, this work may not be reproduced, resold, distributed, or modified without the express permission of The Electrochemical Society (ECS). The archival version of this work was published in the Journal of the Electrochemical Society.

Publisher's link: http://dx.doi.org/10.1149/1.1838575

DOI: $10.1149 / 1.1838575$

This Article is brought to you by the Chemical Engineering, Department of at Scholar Commons. It has been accepted for inclusion in Faculty Publications by an authorized administrator of Scholar Commons. For more information, please contact digres@mailbox.sc.edu. 


\title{
Characterization of Hydrogen Permeation Through Zinc-Nickel Alloys under Corroding Conditions
}

\author{
Mathematical Model and Experimental Study
}

\author{
M. Ramasubramanian, ${ }^{*}$ B. N. Popov, ${ }^{* *}$ and R. E. White** \\ Center for Electrochemical Engineering, Department of Chemical Engineering, University of South Carolina, \\ Columbia, South Carolina 29208, USA
}

\begin{abstract}
A matiematical model was developed for the characterization of hydrogen permeation into metals and alloys under corroding conditions. The model requires a knowledge of the corrosion rate of the given metal or alloy in solutions of various $\mathrm{H}^{+}$concentrations. It provides quantitative values of rate constants of the hydrogen discharge, recombination, and adsorption reactions. This model can serve as a diagnostic criterion for determining the effectiveness of various metals and alloys as hydrogen permeation inhibitors and can be used for evaluation of hydrogen entry inhibition efficiency. Experiments were carried out to study the effectiveness of thin layers of electrodeposited $\mathrm{Zn}-\mathrm{Ni}$ alloys to inhibit hydrogen permeation into iron. The experimental permeation data obtained for $\mathrm{Zn}$-Ni-coated iron were analyzed using the model and the results were compared with the hydrogen permeation characteristics of bare iron.
\end{abstract}

\section{Introduction}

The practical use of ultrahigh-strength alloys is limited by cracking hazards due to hydrogen penetration and hydrogen accumulation in the bulk of the alloy. Hydrogen evolution, and hence its permeation, is usually encountered during electrochemical processes such as electroplating, corrosion, and cathodic protection. In weakening alloys, hydrogen tends to accumulate in areas of high stress and can reach critical concentration causing microcracking to occur, which can lead to a catastrophic fracture that camages the structure. A major portion of the methods suggested for the reduction of hydrogen permeation involves the deposition of a metal, alloy, or resistive coating on the surface that needs to be protected. Deposited alloys or coatings reduce hydrogen embrittlement by acting as a barrier film for hydrogen entry or by changing the kinetics of hydrogen evolution at the surface. Deposition of thin $\mathrm{Zn},{ }^{1} \mathrm{Ni},{ }^{2} \mathrm{Sn}$, or $\mathrm{Cd}^{3}$ layers have been shown to reduce the amount of hydrogen permeating into iron. Zinc-nickel alloys, which are widely used as corrosion protective coatings on steel, have also been studied as hydrogen permeation inhibitors. ${ }^{4}$

There has been significant research in modeling the hydrogen permeation through metals. ${ }^{5-9}$ Iyer et al..$^{9}$ developed a model for the steady-state hydrogen permeation under coupled discharge-chemical recombination conditions that can be used to determine the kinetic parameters for hydrogen evolution and permeation through a membrane under various degrees of cathodic polarization. However, investigations to determine the permeation characteristics under corroding conditions are very uncommon, because there is no theoretical treatment for the determination of hydrogen permeation characteristics under various corroding conditions. Thus, in order to evaluate different alloys for their hydrogen permeation inhibition capabilities, the development of a mathematical model that quantifies the corrosion and hydrogen permeation current on various substrates is an essential step.

The objective of this study was to develop a mathematical model for determining the kinetic constants for different metals and alloys under corroding conditions and to provide a quantitative criterion for evaluation of their hydrogen permeation inhibiting efficiency. The numerical values for various reaction rates and other defined constants obtained from the model can be used as a basis for comparing the hydrogen entry efficiency of different alloys and metals under natural corroding conditions.

The model was used to quantitatively evaluate the effectiveness of the hydrogen permeation inhibition of $\mathrm{Zn}-\mathrm{Ni}$

* Electrochemical Society Student Member

** Electrochemical Society Active Member. alloys. Experiments were carried out to determine the deposition and hydrogen permeation characteristics of $\mathrm{Fe}$ and $\mathrm{Zn}-\mathrm{Ni}$ alloys under various corroding conditions. Values for the various kinetic constants that were obtained by applying the experimental data to this model were compared in the case of $\mathrm{Zn}-\mathrm{Ni}$ and $\mathrm{Fe}$.

\section{Experimental}

The Devanathan-Stachurski ${ }^{5}$ permeation cell was used to study the hydrogen permeation characteristics of bare iron and zinc-nickel alloys under corroding conditions. A $0.1 \mathrm{~mm}$ thick iron foil $(5 \times 5 \mathrm{~cm}$, Goodfellow Corp.) of approximately $4 \mathrm{~cm}^{2}$ area was used. Before the permeation experiments, the membrane was polished using $0.5 \mu \mathrm{m}$ alumina powder to a mirror finish, cleaned, and saturated with hydrogen in $0.1 \mathrm{~N} \mathrm{H}_{2} \mathrm{SO}_{4}$ solution with a cathodic current of $10 \mathrm{~mA} / \mathrm{cm}^{2}$ for $10 \mathrm{~h}$ in a two-electrode cell. The membrane was removed from the cell, rinsed with deionized water, and dried in air. Hydrogen permeation experiments were carried out in a two-compartment system, separated by the iron membrane. The current on the anodic side of the membrane was continuously monitored after setting the potential to a value of $-0.3 \mathrm{~V}$ vs. a $\mathrm{Hg} / \mathrm{HgO}$ reference electrode. On the cathodic side, the membrane was exposed to solutions of $0.5 \mathrm{M} \mathrm{Na}_{2} \mathrm{SO}_{4}$ and $0.5 \mathrm{M} \mathrm{H}_{3} \mathrm{BO}_{3} ; \mathrm{pH}$ was adjusted by adding either $\mathrm{H}_{2} \mathrm{SO}_{4}$ or $\mathrm{NaOH}$. The corrosion rates were measured periodically by carrying out linear polarization and Tafel extrapolation experiments on the cathodic side of the membrane.

To avoid dissolution or passivation and to maintain consistency in the permeation current data, a thin layer of palladium was plated on the anodic side. ${ }^{10}$ The deposition was carried out using $1 \times 10^{-4} \mathrm{M}$ potassium tetranitropalladate at a current density of $200 \mu \mathrm{A} / \mathrm{cm}^{2}$ for $1 \mathrm{~h}$. The compartment was then filled with a $0.2 \mathrm{M} \mathrm{NaOH}$ solution. Both the anodic and cathodic solutions were pre-electrolyzed for $24 \mathrm{~h}$. In order to keep the solutions devoid of dissolved oxygen, prepurified nitrogen was purged through both compartments.

Zinc-nickel alloy was deposited on the cathodic side from a stagnant solution containing $0.5 \mathrm{M} \mathrm{NiSO}_{4}+0.2 \mathrm{M}$ $\mathrm{ZnSO}_{4}+0.5 \mathrm{M} \mathrm{Na}_{2} \mathrm{SO}_{4}$ at a pH of 3.0. Plating was carried out for either 20 or $45 \mathrm{~min}$ at $-1.2 \mathrm{~V}$ vs. SCE. The deposited surface was subsequently exposed to cathodic solutions of different $\mathrm{pH}$. Corrosion rates were obtained periodically. The corrosion potential was continuously monitored in the cathodic compartment while tracking the permeation current density in the anodic compartment. Zinc-nickel alloy stability studies were also carried out by immersing the electrodeposited $\mathrm{Zn}-\mathrm{Ni}$ alloys in a solution containing $0.5 \mathrm{M} \mathrm{Na}_{2} \mathrm{SO}_{4}+0.5 \mathrm{M} \mathrm{H}_{3} \mathrm{BO}_{3}$ at various $\mathrm{pH}$ values obtained by adding either $\mathrm{H}_{2} \mathrm{SO}_{4}$ or $\mathrm{NaOH}$. 


\section{Model}

A schematic of the system considered for developing the model for hydrogen permeation through a single metal layer under corroding conditions is given in Fig. 1. The underlying assumptions for the model are as follows: (i) hydrogen evolution is the only cathodic reaction; (ii) within the membrane, hydrogen permeation occurs only by diffusion of absorbed hydrogen; (iii) the absorption-adsorption and oxidation reactions on the exit side are much faster than the entrance side; (iv) the membrane is homogenous with no defects and hence there are no hydrogen trapping sites; $(v)$ the process is at steady state; and (vi) the adsorbed $\mathrm{MH}$ molecules follow the Langmuir adsorption isotherm.

Assumption (i) was maintained during the course of the experiments by continuously bubbling nitrogen and thereby ensuring the dissolved oxygen content to be very low. From Fig. 1 and assumption (iv), one can see that the hydrogen atom flux at the exit side of the membrane, $N_{\text {perm }}$, is the flux across each interface. Thus, at the metal-electrolyte interface

$$
N_{\text {perm }}=N_{\mathrm{H}}=N_{\text {ads }}-N_{\text {des }}
$$

where $N_{\text {ads }}$ is the rate at which the adsorbed species is being produced, and $N_{\text {des }}$ is the desorption rate. The expressions for $N_{\text {ads }}$ and $N_{\text {des }}$ depend on the mechanism of hydrogen evolution on the specific metal. The hydrogen flux at the interface between the membrane and the adsorbed layer can be presented as

$$
N_{\mathrm{H}}=N_{\text {abs }}-N_{\text {rab }}
$$

where $N_{\text {abs }}$ is the flux of absorbed hydrogen atoms, and $N_{\text {rab }}$ is the flux of hydrogen atoms that revert to an adsorbed state from an absorbed state.

Finally, the exit hydrogen flux at steady state is

$$
N_{\mathrm{H}}=-D \frac{d C}{d x}
$$

where $D$ is the diffusion coefficient of hydrogen in the membrane and $C$ is the concentration of hydrogen atoms along the thickness of the membrane. Under conditions where hydrogen permeation experiments are carried out, the concentration at the exit side, $x=L$, is maintained at zero by oxidizing the hydrogen instantaneously at the surface. The absorbed hydrogen concentration at the entrance

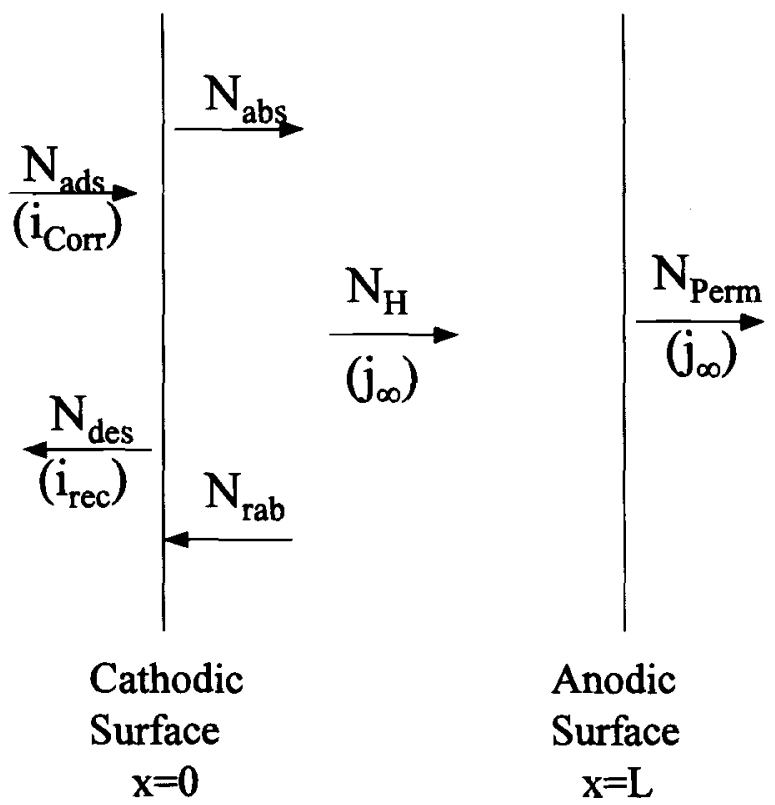

Fig. 1. Schematic representation of the hydrogen permeation modeling region. side, $x=0$, can be denoted by $C_{\text {abs. }}$. Hence Eq. 3 can be modified as

$$
N_{\mathrm{H}}=\frac{-D\left(C_{\mathrm{abs}}-0\right)}{(0-L)}=\frac{D C_{\mathrm{abs}}}{L}
$$

Hydrogen evolution by a coupled discharge-electrochemical recombination mechanism.-The coupled dischargeelectrochemical recombination mechanism for the evolution of hydrogen can be represented as follows ${ }^{11}$

$$
\begin{gathered}
\mathrm{M}+\mathrm{H}^{+}+\mathrm{e}^{-} \stackrel{k_{1}}{\rightarrow} \mathrm{MH}_{\mathrm{ads}} \\
\mathrm{MH}_{\mathrm{ads}}+\mathrm{H}^{+}+\mathrm{e}^{-} \stackrel{k_{2}}{\rightarrow} \mathrm{H}_{2}+\mathrm{M}
\end{gathered}
$$

Under coupled discharge conditions, both these steps proceed under a comparable rate, and the overall rate is determined by the rate of both these steps combined. The flux of hydrogen adsorption in Eq. 1 can be written as

$$
N_{\mathrm{ads}}=\frac{i_{\mathrm{c}}}{z F}=k_{1}(1-\theta) C_{\mathrm{H}^{+}}^{\mathrm{p}} \exp (-\alpha f \eta)
$$

where $k_{1}$ is the rate constant of the electrochemical discharge reaction (Eq. 5), $(1-\theta)$ is the fraction of free surface available for reduction of $\mathrm{H}^{+}$ions, and $\mathrm{C}_{\mathrm{H}^{+}}$is the concentration of $\mathrm{H}^{+}$ions at the electrode-electrolyte interface. The rate constant $k_{1}$, in a noncorrosive environment, depends on the exchange current density $\left(i_{o}\right)$ of hydrogen evolution on the specific metal. Under corroding conditions, $k_{1}$ depends on the corrosion current density $\left(i_{c}\right)$ of the system. The overpotential, $\eta$, for the hydrogen evolution reaction is given by

$$
\eta=E_{\text {corr }}-E_{1}^{\text {o }}
$$

where $E_{\text {corr }}$ is the corrosion potential and $E_{1}^{0}$ is the standard electrode potential for hydrogen evolution on the specific substrate. In order to describe the potential value accurately, the term $E_{1}^{\circ}$ should be substituted by a concentration dependent term $E_{1}$, which can be determined by the Nernst equation. However, for the purposes of this study, the concentration-dependent component of the overpotential can be separated and included in the $C_{\mathrm{H}^{+}}$term. This concentration dependence, along with other thermodynamic and kinetic nonidealities such as the change in activity of the hydrogen ion and the actual available concentration at the electrode surface (rather than at the bulk), can be combined into a single nonideality parameter denoted as $p$ in Eq. 7. Thus, the term $C_{\mathrm{H}^{+}}^{\mathrm{p}}$ denotes an effective $\mathrm{H}^{+}$concentration, which affects the value of the cathodic discharge current.

The recombination reaction flux can be written as

$$
N_{\text {des }}=\frac{i_{\mathrm{r}}}{z F}=k_{2} \theta C_{\mathbf{H}^{+}}^{\mathrm{q}} \exp (-\alpha f \eta)
$$

where $k_{2}$ is a constant which is a product of the rate constant of the recombination reaction and the maximum adsorbable concentration of $\mathrm{H}^{+}$on the metal surface. Again, the nonideality term $q$ is associated with the effective hydrogen concentration for the recombination reaction. From Eq. 1 one obtains

$$
N_{\mathrm{H}}=k_{1}(1-\theta) C_{\mathrm{H}^{+}}^{\mathrm{p}} \exp (-\alpha f \eta)-k_{2} \theta C_{\mathrm{H}^{+}}^{\mathrm{q}} \exp (-\alpha f \eta)
$$

The hydrogen absorption into the metal matrix is given by

$$
\mathrm{MH}_{\mathrm{ads}} \rightleftarrows \mathrm{MH}_{\mathrm{abs}}
$$

This adsorption-absorption reaction is assumed to be in equilibrium, with $k_{3}$ and $k_{4}$ being the absorption and adsorption rate constants, respectively. The flux for the absorption reaction is given by

$$
N_{\mathrm{abs}}=k_{3} \theta
$$

while the flux for the reverse absorption reaction is

$$
N_{\text {rab }}=k_{4}(1-\theta) C_{\mathrm{abs}}
$$


where $C_{\text {abs }}$ is the concentration of absorbed hydrogen atoms adjacent to the adsorbed layer. From Eq. 2, 12, and 13, we get

$$
N_{\mathrm{H}}=k_{3} \theta-k_{4}(1-\theta) C_{\text {abs }}
$$

Equations 3,10, and 14 can then be used to eliminate the unknowns $C_{\text {abs }}$ and $\theta$ and obtain a relationship for the permeation flux as a function of the $\mathrm{H}^{+}$concentration at the interface, $\mathrm{C}_{\mathrm{H}^{+}}$. The resultant equation for the dependence of the permeation flux on the $\mathrm{H}^{+}$concentration is nonlinear. Under corroding conditions, where the current density is low, one can assume that the fraction of surface covered by $\mathrm{MH}_{\mathrm{ads}}$ is very small. Hence Eq. 14 can be simplified to

$$
N_{\mathrm{H}}=\frac{j_{\varkappa}}{z F}=k_{3} \theta-k_{4} C_{\mathrm{abs}}
$$

According to Eq. 3

$$
N_{\mathrm{H}}=\frac{j_{x}}{z F}=\frac{D C_{\mathrm{abs}}}{L}
$$

By eliminating $C_{\mathrm{abs}}$ from these two equations one obtains

$$
\theta=\frac{j_{x}}{z F k_{\mathrm{a}}}
$$

where

$$
k_{\mathrm{a}}=\frac{k_{2}}{\left(1+k_{4} \frac{L}{D}\right)}
$$

is a thickness dependent adsorption-absorption constant. The dimensionless group $\left(k_{4} L / D\right)$ can be interpreted as the relative rate of the reverse-absorption and the diffusion process. If $D / L \gg k_{4}$, the term in Eq. 18 can be neglected and the permeation will be controlled by either the charge transfer or by the surface process. If $k_{3}$ is very large and $D / L$ is comparable to or less than $k_{4}$, the process will be controlled by diffusion.

In the case of the samples coated with $\mathrm{Zn}-\mathrm{Ni}$, or any other system with multiple layers, the equation for hydrogen flux at the anodic side, Eq. 16 has to be modified as

$$
N_{\mathrm{H}}=\frac{j_{x}}{z F}=\frac{D_{1} C_{1}}{L}=\frac{D_{2}\left(C_{\mathrm{abs}}-C_{1}\right)}{L_{2}}
$$

where $L_{2}$ is the thickness of the $\mathrm{Zn}-\mathrm{Ni}$ alloy coating and $D_{1}$ and $D_{2}$ are the diffusion coefficients of hydrogen in the substrate and the alloy coating, respectively. $C_{1}$ in Eq. 19 can be written in terms of the permeation current density and can be subsequently substituted and rearranged to give

$$
N_{\mathrm{H}}=\frac{j_{x}}{z F}=\frac{D_{2} C_{\mathrm{abs}}}{L_{2}\left(1+\frac{D_{2} L}{L_{2} D_{1}}\right)}=\frac{D_{\text {eff }} C_{\text {abs }}}{L_{2}}
$$

where

$$
D_{\text {eff }}=\frac{D_{2}}{\left(1+\frac{D_{2} L}{L_{2} D_{1}}\right)}
$$

Hence, the form represented in Eq. 17 would still be valid, and the adsorption-absorption constant, $k_{a}$, would now be

$$
k_{\mathrm{a}}=\frac{k_{3}}{\left(1+k_{4} \frac{L_{2}}{D_{\text {eff }}}\right)}
$$

Under corroding conditions, linear polarization or a Tafel extrapolation method can be used to determine the corrosion current density. The estimated corrosion current density corresponds to a steady-state cathodic current density $\left(i_{\mathrm{c}}\right)$. A recombination current density can also be calculated by the following relationship under steady state, which is another form of Eq. 1

$$
j_{\infty}=i_{\mathrm{c}}-i_{\mathrm{r}}
$$

Using Eq. 4, 10, 14, and 23, we can obtain the relationships between $i_{\mathrm{r}}, j_{x}$, and the concentration of hydrogen as

$$
\frac{i_{\mathrm{r}} \exp (\alpha f \eta)}{j_{x}}=\frac{k_{2}}{k_{\mathrm{a}}} C_{\mathrm{H}^{+}}^{\mathrm{q}}
$$

A plot of $\log \left[i_{\mathrm{r}} \exp (\alpha f \eta) / j_{\infty}\right]$ vs. $\log \left(\mathrm{C}_{\mathrm{H}^{+}}\right)$has a slope of the parameter $q$ and an intercept of $\log \left(k_{2} / k_{\mathrm{a}}\right)$.

Under low surface coverage conditions, the cathodic current density can be written as

$$
i_{\mathrm{c}}=z F k_{1} C_{\mathrm{H}^{+}}^{\mathrm{p}} \exp (-\alpha f \eta)
$$

A plot of the values of $\log \left[i_{\mathrm{c}} \exp (\alpha f \eta)\right]$ vs. $\log \left(C_{\mathrm{H}^{+}}\right)$has a slope of $p$ and an intercept of $\log \left(z F k_{1}\right)$. In order to evaluate the rate constant for the discharge reaction, $k_{1}$ and the recombination rate constant $k_{2}$, the value of $\theta$ in Eq. 7 can be substituted with Eq. 17 to obtain

$$
i_{\mathrm{c}} \exp (\alpha f \eta) C_{\mathrm{H}^{+}}^{\mathrm{p}^{-1}}=z F k_{1}-\frac{k_{1}}{k_{\mathrm{a}}} j_{x}
$$

From a plot of $\left[\exp (\alpha f \eta) i_{\mathrm{c}}\left(C_{\mathrm{H}^{+}}\right)^{1 / \mathrm{p}}\right]$ vs. $j_{\infty}$, values for $k_{1}$ and $k_{1} / k_{\mathrm{a}}$ can be determined. Thus, using the values of the slopes and intercepts from the plot, one can determine the individual rate constants for the hydrogen evolution reaction.

Hydrogen evolution by a coupled discharge-chemical recombination mechanism.-A similar mathematical model can be developed to determine the reaction rate constants for metals on which hydrogen evolution occurs by a chemical recombination following an electrochemical discharge step. The recombination reaction in a coupled dischargechemical recombination mechanism is described by

$$
\mathrm{MH}_{\text {ads }}+\mathrm{MH}_{\mathrm{ads}} \rightarrow \mathrm{H}_{2}+2 \mathrm{M}
$$

According to Eq. 27, the recombination flux can be denoted by

$$
N_{\mathrm{des}}=\frac{i_{\mathrm{r}}}{z F}=k_{2} \theta^{2}
$$

Following the procedure as in the previous mechanism, one can obtain the following relationship between the recombination current, cathodic (corrosion) current, and the hydrogen ion concentration

$$
\begin{gathered}
i_{\mathrm{r}}=\frac{k_{2}}{z F k_{\mathrm{a}}^{2}} j_{s}^{2} \\
i_{\mathrm{c}}=z F k_{1}(1-\theta) C_{\mathrm{H}^{+}}^{\mathrm{p}} \exp (-\alpha f \eta) \\
i_{\mathrm{c}} \exp (\alpha f \eta) C_{\mathrm{H}^{+}}^{\mathrm{p}^{-1}}=z F k_{1}-\frac{k_{1}}{k_{\mathrm{a}}} j_{\infty}
\end{gathered}
$$

The mechanism is valid if the plot of $i_{\mathrm{r}}$ vs. $j_{\infty}^{2}$ is linear and passes through the origin. As in the previous mechanism, the plots of $i_{\mathrm{r}}$ vs. $j_{x}^{2}, \log \left[i_{\mathrm{c}} \exp (\alpha f \eta)\right]$ vs. $\log \left(C_{\mathrm{H}^{+}}\right)$and $\left[\exp (\alpha f \eta) i_{\mathrm{c}}\left(C_{\mathrm{H}^{+}}\right)^{1 / \mathrm{p}}\right]$ vs. $j_{\mathrm{x}}$ can be used to obtain the constants $k_{1}, k_{2}$, and $k_{\mathrm{a}}$

\section{Results and Discussion}

$\mathrm{Zn}$-Ni alloy stability studies.-In order to determine the composition of the electrolyte in which the alloy would not dissolve appreciably for substantial amounts of time, it was necessary to investigate the effect of $\mathrm{pH}$ on $\mathrm{Zn}-\mathrm{Ni}$ alloy corrosion. Figure 2 shows the $E_{\text {corr }}$-time curves obtained from the experiments carried out for $\mathrm{Zn}-\mathrm{Ni}$ alloys deposited at $-1.2 \mathrm{~V}$ (SCE) for $20 \mathrm{~min}$, with zinc content between 88 and $91 \%$ and the thickness in the range of $3-4 \mu \mathrm{m}$. The plot indicates that the alloy is unstable in its initial form in acidic solutions. The plot obtained at $\mathrm{pH} 3.0$ shows an initial potential shift toward a more positive value. Previous studies carried out for determining the structure of zinc-nickel alloys ${ }^{12-14}$ with $88-91 \%$ zinc suggest that the 


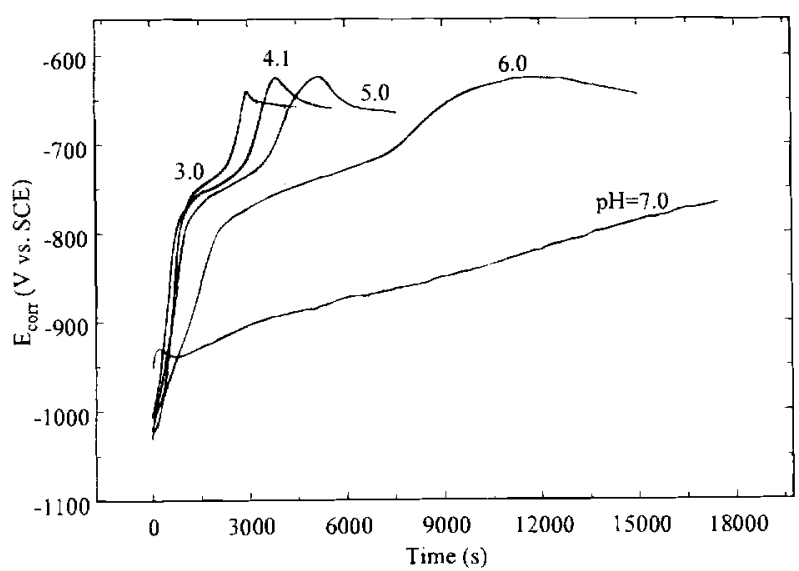

Fig. 2. $E_{\text {corr }}$ vs. time plots for electrodeposited $\mathrm{Zn}-\mathrm{Ni}$ alloys (deposition time $20 \mathrm{~min}$ ) immersed in $0.5 \mathrm{M} \mathrm{Na}_{2} \mathrm{SO}_{4}+0.5 \mathrm{M}$ $\mathrm{H}_{3} \mathrm{BO}_{3}$ at different $\mathrm{pH}$.

alloy is predominantly in the $\gamma$ phase. Stripping voltammograms measured on zinc-nickel films ${ }^{13,14}$ show the dissolution of zinc-rich phases at cathodic overpotentials between -0.7 and $-0.9 \mathrm{~V}$ (SCE). Hence, one can assume that the potential shift is caused by the dissolution of zinc or the zinc rich $(\gamma)$ phase from the zinc-nickel alloy. The potential shifts from a value close to that of zinc toward that of iron and stabilizes at around $-0.675 \mathrm{~V}$ (SCE). As expected, the dissolution of the alloy is slower as the $\mathrm{pH}$ increases. At $\mathrm{pH}$ 7.0 , the alloy is stable for substantial amounts of time. Figure 3 shows the $E_{\text {corr }}$ vs. time plots for a thicker $\mathrm{Zn}-\mathrm{Ni}$ alloy electrodeposited at $-1.2 \mathrm{~V}$ (SCE) for $45 \mathrm{~min}$ with a thickness of $6-8 \mu \mathrm{m}$. It can be seen that this alloy is stable for significantly longer times. Thus, the hydrogen permeation studies were carried out in moderately acidic conditions ( $\mathrm{pH} 4.5-7.0$ ) on $\mathrm{Zn}-\mathrm{Ni}$ alloys deposited for $45 \mathrm{~min}$.

Hydrogen permeation of $\mathrm{Zn-Ni}$ alloys under cathodically polarized conditions.- The hydrogen entry efficiency of the $\mathrm{Zn}-\mathrm{Ni}$ alloys was determined as opposed to its values on bare iron under cathodic polarization conditions. The experiments were carried out under conditions of controlled applied overpotential $\left(\eta_{\mathrm{k}}\right)$, which is defined in this case as the potential difference between the applied value and the corrosion potential. The readings for the cathodic current and the permeation current were determined at the same levels of applied overpotential for the iron and $\mathrm{Zn}-\mathrm{Ni}$ samples rather than at various cathodic potential values. This eliminates the problem of comparing two alloys at different levels of polarization, which would be the case if the experiments were carried out under con-

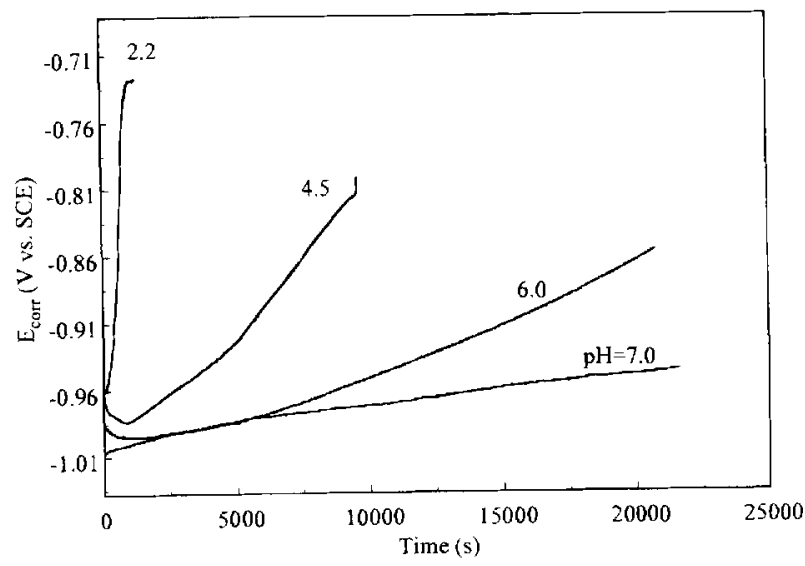

Fig. 3. $E_{\text {corr }}$ vs. time plots for electrodeposiled $\mathrm{Zn}-\mathrm{Ni}$ alloys (deposition time $45 \mathrm{~min}$ ) immersed in $0.5 \mathrm{M} \mathrm{Na}_{2} \mathrm{SO}_{4}+0.5 \mathrm{M}$ $\mathrm{H}_{3} \mathrm{BO}_{3}$ at different $\mathrm{pH}$. stant potential conditions due to a large difference in the open-circuit potentials of iron and $\mathrm{Zn}-\mathrm{Ni}$. The experiment could be carried under controlled cathodic current conditions; however, the inherent increase in the experimental error with potential as a dependent variable makes this technique undesirable. A plot of the steady-state cathodic and permeation currents vs. the applied overpotential $\left(\eta_{\mathrm{a}}\right)$ is shown in Fig. 4. As seen from the plot, under the same applied overpotential, the cathodic current obtained on iron is smaller than the current obtained for $\mathrm{Zn}-\mathrm{Ni}$ samples. If a constant potential analysis had been applied, the current observed for the iron would be greater than that of the alloy. The open-circuit potentials obtained in a solu-

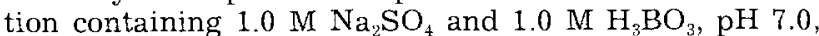
were -0.725 and $-1.138 \mathrm{~V}$ (SCE) for bare $\mathrm{Fe}$ and $\mathrm{Zn}-\mathrm{Ni}$ alloy, respectively. In the case of pure iron, the permeation current is very high and increases with the increasing overpotential. Also, as shown in Fig. 4, a large increase of the permeation current with the applied overpotential was observed on bare iron. The Zn-Ni alloy shows lesser permeation current as compared to a greater hydrogen evolution rate. The increase in the permeation current with an increase in the applied overpotential is much smaller than the increase observed on bare iron. It is known that the kinetics of hydrogen evolution is faster in $\mathrm{Zn}-\mathrm{Ni}$ than in $\mathrm{Fe}$. Hence, the reduction in permeation current in the presence of a $\mathrm{Zn}-\mathrm{Ni}$ coating at a given applied overpotential can be attributed to: (i) a decrease in the ratio of absorbed to adsorbed hydrogen on a $\mathrm{Zn}-\mathrm{Ni}$ surface or (ii) a decrease in the diffusion coefficient of hydrogen in $\mathrm{Zn}-\mathrm{Ni}$. If a decrease in the diffusion coefficient were to cause the reduction in the permeation current, then the reduction would be a function of the alloy thickness. A change in the adsorption-absorption ratio would not be a function of thickness as long as the composition is maintained intact. Further experiments are being carried out in order to distinguish between these two factors and are the subject of a future publication.

Hydrogen permeation analysis under corroding conditions.-Figure 5 shows a plot of the permeation transient of a $\mathrm{Zn}-\mathrm{Ni}$ alloy deposited at $-1.2 \mathrm{~V}$ (SCE) for $45 \mathrm{~min}$ and subsequently immersed in a solution containing $0.5 \mathrm{M}$ $\mathrm{Na}_{2} \mathrm{SO}_{4}$ and $0.5 \mathrm{M} \mathrm{H}_{3} \mathrm{BO}_{3}$ at a pH of 4.5. The plot shows the dependence of the permeation current on the potential of the $\mathrm{Zn}-\mathrm{Ni}$ alloy in the cathodic compartment. The cathodic solution was added at time $t=0$, and both the potential in the cathodic side and the permeation current density in the anodic side were monitored continuously. The corrosion potential on the cathodic compartment initially shifts in the cathodic direction. This can be attributed to the

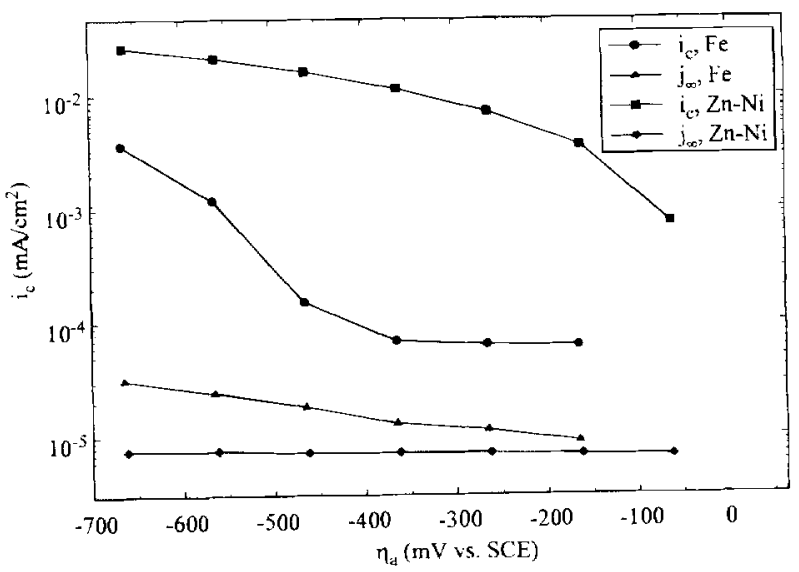

Fig. 4. Steady-state cathodic and permeation current densities for $\mathrm{Fe}$ and an electrodeposited $\mathrm{Zn}-\mathrm{Ni}$ alloy at various applied cathodic overpotentials $\left(\eta_{\mathrm{a}}\right)$. The applied overpotential denotes the difference between the applied potential and the corrosion potential of the metal or the alloy. 


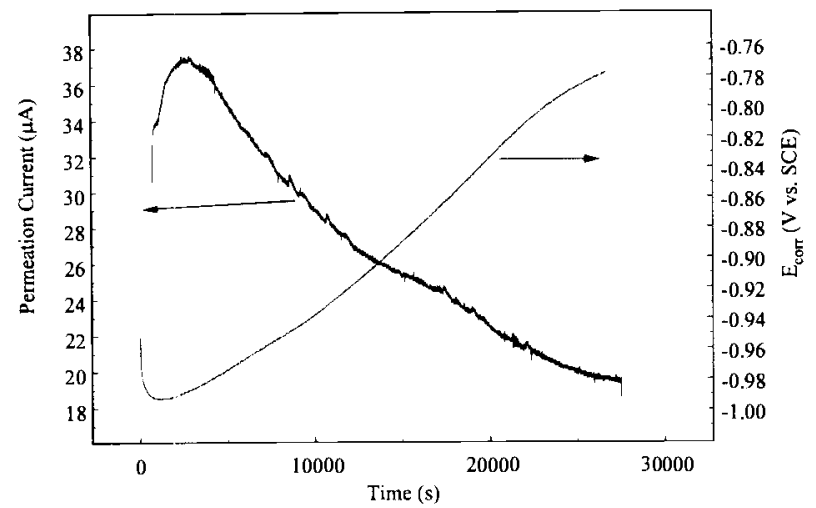

Fig. 5. A plot of the permeation current density (in the anodic compartment) and the corrosion potential (in the cathodic compartment) for an electrodeposited $\mathrm{Zn}-\mathrm{Ni}$ alloy immersed in a solution of $\mathrm{pH}$ 5.2.

slight dissolution of the passivated zinc oxide layer in the alloy. This causes a slight decrease in the corrosion current during the initial periods of time. This decrease in corrosion current causes an inflection in the increasing permeation current during the initial periods. However, the passive layer dissolution causes the corrosion potential to shift in the cathodic direction, which increases the driving force for the galvanic corrosion reaction between any exposed $\mathrm{Fe}$ (substrate) or $\mathrm{Ni}$ (deposit) and $\mathrm{Zn}$, which in turn forces the corrosion current to increase. Hence, the corrosion current goes through a maximum at some point between zero and the time needed for the cathode potential to reach a minimum. Since there is a time lag associated with hydrogen adsorption, absorption, and permeation, the maximum in the permeation current, associated with the maximum in corrosion current, occurs at a later time. As shown in Fig. 5, the permeation current density response is fairly fast, and the value of $j_{\infty}$ reaches a maximum at about $3000 \mathrm{~s}$, whereas the minimum in the potential occurs near $1000 \mathrm{~s}$. The maximum is thus a result of the competition between the corrosion rate decrease as a result of zinc dissolution and the permeation current increase due to a higher corrosion rate at an earlier time. For such $\mathrm{pH}$ conditions, where the permeation current goes through a maximum, the maximum value is taken as the steady-state permeation current density. These values were subsequently verified by determining the steadystate permeation current density and by maintaining the cathodic potential at a constant value equal to their initial open-circuit potential.

As shown in Fig. 6, for electrolytes more alkaline than a $\mathrm{pH}$ of 4.5 , the permeation current densities remain relatively constant near the maximum values. This is because the rate of dissolution of $\mathrm{Zn}-\mathrm{Ni}$ alloy is significantly slower at low hydrogen concentrations. Accordingly, in this study, the hydrogen steady-state permeation values determined at $\mathrm{pH}$ higher than 4.5 were used to calculate the reaction rate constants.

Figure 7 shows a plot of the recombination function $\log \left[i_{\mathrm{r}} \exp (\alpha f \eta) / j_{x}\right]$ vs. the concentration term $\log \left(C_{\mathrm{H}^{\prime}}\right)$. The term $\exp (-\alpha f \eta)$ describes the dependence of the cathodic current on the overpotential. The overpotential under corroding conditions is defined in Eq. 8 as a difference between the corrosion and equilibrium potentials for hydrogen evolution. An increase in $\mathrm{H}^{+}$concentration causes the value of the equilibrium potential $E^{\circ}$ to become more cathodic. Thus, under constant kinetic conditions, the overpotential will increase with an increase in hydrogen ion concentration, which causes the exponential term to increase. Accordingly, the inverse of the exponential term, $\exp (\alpha f \eta)$ will decrease with an increase of the proton concentration. The term $i_{\mathrm{r}} / j_{x}$, the ratio of the recombination current to the permeation current, is a material-specific characteristic which either decreases or increases with an increase of the

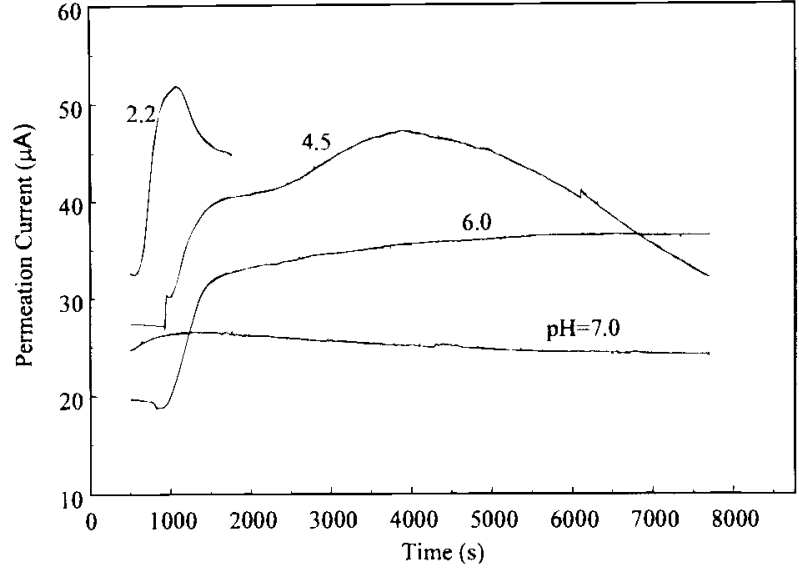

Fig. 6. Permeation current densities for $\mathrm{Zn}-\mathrm{Ni}$ alloys immersed in $0.5 \mathrm{Na}_{2} \mathrm{SO}_{4}+0.5 \mathrm{M} \mathrm{H}_{3} \mathrm{BO}_{3}$ at various $\mathrm{pH}$.

hydrogen ion concentration in the solution. Depending on the relative importance of this product, the slope of the plot can either be positive or negative. As shown in Fig. 7, the slope is positive for the $\mathrm{Zn}-\mathrm{Ni}$ alloy, which indicates that the increase of $i_{\mathrm{r}} / j_{x}$ with the proton concentration is more significant than the decrease of the exponential term in the recombination function. The small magnitude of the decrease of $\exp (\alpha f \eta)$ with $\mathrm{H}^{+}$concentration observed for the $\mathrm{Zn}-\mathrm{Ni}$ alloy was due to the larger overpotential for the $\mathrm{Zn}-\mathrm{Ni}$ alloy than the $\mathrm{Fe}$ overpotential. This is also the reason why the recombination function for the $\mathrm{Zn}-\mathrm{Ni}$ alloy is orders of magnitude lower than that of the recombination function estimated for Fe. According to Fig. 7, as the corrosive nature of the solution increases, the ratio of the recombination to the permeation current densities increases in the case of the $\mathrm{Zn}-\mathrm{Ni}$ alloy. For the case of bare iron, the experiments showed an increase in $i_{\mathrm{r}} / j_{x}$ with an increase in $\mathrm{H}^{+}$concentration in solution. The observed decrease coupled with a larger decrease in the exponential term with increasing proton concentration for $\mathrm{Fe}$ causes a decrease of the recombination function. Thus, an increase in the proton concentration causes significantly greater damage to iron due to its decreasing recombination-to-permeation current density ratio.

Figure 8 shows the relationship between the cathodic charging function $\log \left[i_{\mathrm{c}} \exp (\alpha f \eta)\right]$ and $\log \left(C_{\mathrm{H}}\right)$. The corrosion current $\left(i_{c}\right)$ would be expected to increase with increasing $\mathrm{H}^{+}$concentration, whereas the exponential term would be expected to decrease. Once again, in the case of $\mathrm{Zn}-\mathrm{Ni}$ alloy, because of a higher overpotential, the exponential term is very small and the increase in the cathodic current dominates the product. This gives rise to a positive

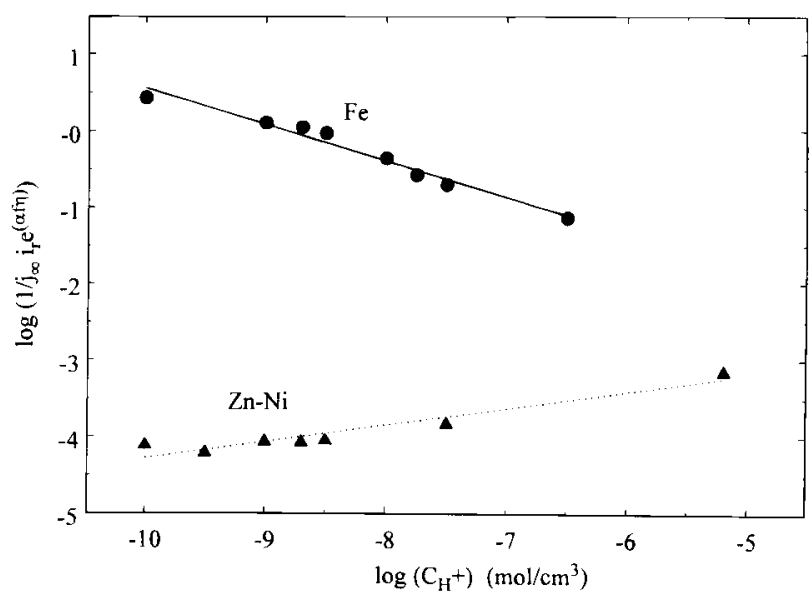

Fig. 7. Recombination function as a function of the hydrogen ion concentration for Fe and $\mathrm{Zn}-\mathrm{Ni}$ alloy. 


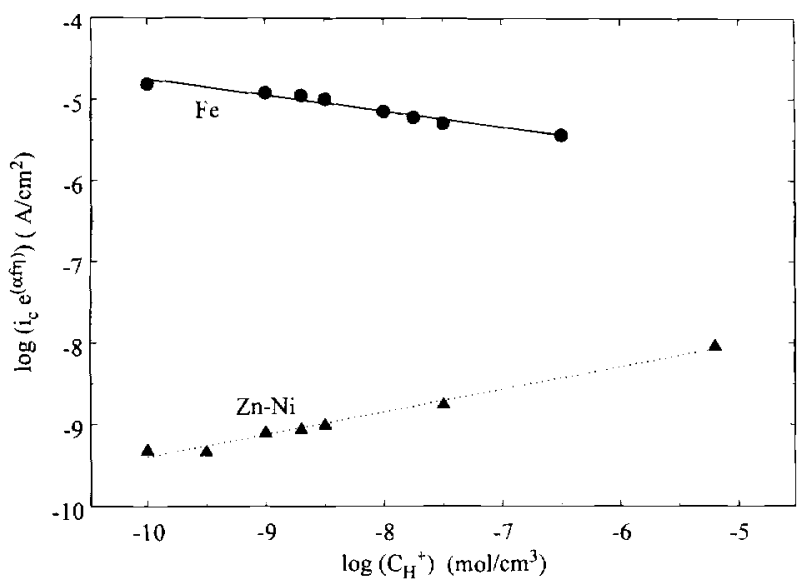

Fig. 8. Plot of the cathodic charging function against the hydrogen ion concentration for Fe and Zn-Ni alloy.

slope for the cathodic charging function. Bare iron shows that the effective concentration for hydrogen evolution is inversely related to the actual proton concentration. In other words, as the actual proton concentration increases, the concentration responsible for hydrogen evolution decreases.

In order to determine the rest of the kinetic constants, a modified cathodic charging function $\left[i_{\mathrm{c}} \exp (\alpha f \eta)\left(C_{\mathrm{H}^{+}}\right)^{1 / \mathrm{p}}\right]$ was plotted against the permeation current density in Fig. 9. Using the slopes and intercepts of these plots one can estimate the rate constants for the adsorption and recombination reaction, the adsorption-absorption equilibrium constant, and the parameters that determine the concentration dependence, $p$ and $q$. The calculated results are summarized in Table I. As shown in Table I, three rate constants and two parameters can be used to quantitatively determine the hydrogen permeation inhibition capabilities of a metal or alloy under corroding conditions. An ideal metal or alloy would have a very small $k_{1}$, very large $k_{2}$, and a very small adsorption-absorption constant $k_{\mathrm{a}}$. It would also have to have a positive value of $q$ and a value of zero for $p$. For the case of a $\mathrm{Zn}-\mathrm{Ni}$ alloy, the obvious disadvantages to its hydrogen permeation inhibitive qualities are its high values of $k_{1}$ and $p$. This alloy is well suited for the protection of bare iron in terms of having a lower adsorption-absorption constant, a positive $q$, and a larger $k_{2}$.

In the case of bare iron, it can be seen from Table I that the values for $p$ and $q$ are negative. According to these results, with an increase in the $\mathrm{H}^{+}$ion concentration the term $C_{\mathrm{H}^{-}}^{\mathrm{p}}$ decreases. This suggests that, with a decrease in $\mathrm{pH}$, the effective concentration responsible for the hydrogen evolution reaction decreases. However, the actual cathodic

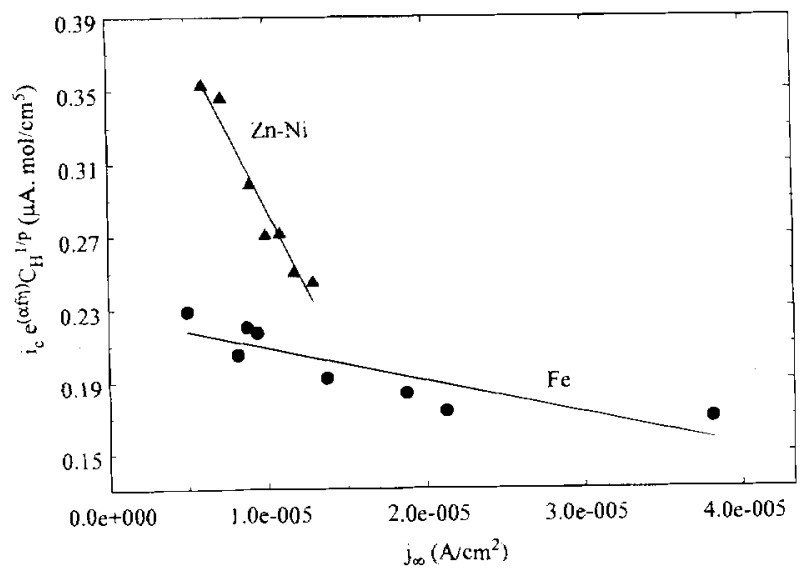

Fig. 9. Modified cathodic charging function against the permeation current density for $\mathrm{Fe}$ and $\mathrm{Zn}-\mathrm{Ni}$ alloy.
Toble I.

\begin{tabular}{lcc}
\hline & $\mathrm{Fe}$ & $\mathrm{Zn}-\mathrm{Ni}$ \\
\hline$k_{1}\left(\mathrm{~mol} / \mathrm{cm}^{2} \mathrm{~s}\right)$ & $1.0 \times 10^{-12}$ & \\
$k_{2}\left(\mathrm{~mol}^{2} \mathrm{~cm}\right)$ & $1.8 \times 10^{-1.3}$ & $3.5 \times 10^{-12}$ \\
$k_{\mathrm{a}}\left(\mathrm{mol} / \mathrm{cm}^{2} \mathrm{~s}\right)$ & $2.85 \times 10^{-9}$ & $4.05 \times 10^{-12}$ \\
$p$ & -0.196 & 0.286 \\
$q$ & -0.476 & 0.227
\end{tabular}

and permeation fluxes, given by Eq. 7 and 9, respectively, do not decrease. This can be attributed to the increase in overpotential with a decrease in $\mathrm{pH}$, which causes the exponential term to increase, thereby offsetting the decrease due to the concentration. Thus, a negative value for $p$ suggests that a change in overpotential due to a change in $\mathrm{H}^{+}$concentration affects the cathodic current density more than the concentration itself. Similarly, the negative value of $q$ suggests that the overpotential is the major determining factor in value of the recombination current density in the presence of various $\mathrm{H}^{+}$concentrations.

The values for the various constants obtained using this model are valid only for the regions under which the assumed mechanism is valid. For example, in the case of bare $\mathrm{Fe}$, the negative values of $p$ and $q$ suggest that, in the limiting case, i.e., as $\mathrm{H}^{*}$ approaches zero, the fluxes given in Eq. 7 and 9, become infinite. However, in alkaline solutions corresponding to very low $\mathrm{H}^{+}$concentrations, hydrogen evolution is accepted to occur by water reduction instead of $\mathrm{H}^{+}$reduction. ${ }^{15}$ Hence, the values obtained in these sets of experiments must be extrapolated only to acidic and slightly acidic regions, where the above-mentioned mechanism is valid.

One of the assumptions in the model is that the surface coverage of adsorbed hydrogen is very small. In order to verify the validity of this assumption, the hydrogen surface coverage was calculated as a function of proton concentration using the constants listed in Table I. Figure 10 shows the hydrogen surface coverage as a function of the hydrogen ion concentration for the $\mathrm{Zn}-\mathrm{Ni}$ alloy and bare Fe. As shown in Fig. 10, the hydrogen surface coverage is small for both substrates. The maximum hydrogen surface coverage was estimated for $\mathrm{Zn}-\mathrm{Ni}$ alloy to be 0.16 . These results suggested that the Langmuir adsorption isotherm can be used to approximate the surface coverage behavior.

\section{Conclusions}

A mathematical model was developed for the characterization of hydrogen permeation onto metals and alloys under corroding conditions. The model takes into account the dependence of the corrosion rate on the $\mathrm{H}^{+}$ion concentration. It provides a tool to estimate quantitatively the values of $(i)$ the reaction rate constants for the adsorption and recombination reactions $\left(k_{1}\right.$ and $\left.k_{2}\right)$, (ii) the adsorption-absorption

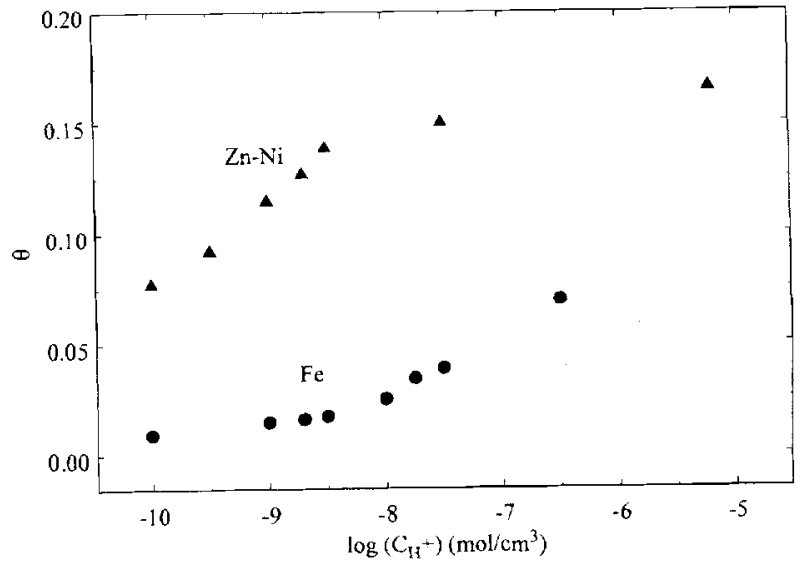

Fig. 10. Surface coverage of adsorbed hydrogen as a function of the hydrogen ion concentration for Fe and $\mathrm{Zn}-\mathrm{Ni}$ alloy. 
constant $\left(k_{\mathrm{a}}\right)$, and (iii) the factors that determine the effective $\mathrm{H}^{+}$concentrations for the adsorption and recombination reactions, $p$ and $q$, respectively. The model can be used for metals or alloys that undergo hydrogen evolution with either an electrochemical or chemical discharge mechanism in the region where the mechanism is valid.

Experiments were carried out to determine the suitability of using $\mathrm{Zn}-\mathrm{Ni}$ alloys as inhibitive layers for hydrogen permeation on steel. The experimental data has been successfully arialyzed using the mathematical model. It was shown that the $\mathrm{Zn}-\mathrm{Ni}$ alloy provides desirable qualities to serve as a hydrogen permeation inhibitor, such as a low value of the adsorption-absorption constant, which suggests that the recombination rate is high. The model also identifies the areas where the capabilities of the $\mathrm{Zn}-\mathrm{Ni}$ alloys for hydrogen permeation inhibition could be improved. For example, the value of $k_{1}$, the rate constant for the hydrogen discharge reaction, could be reduced to obtain better inhibition efficiency. This reduction is possible by the addition of certain alloying ternary elements. The purpose of the alloying element would be to bring the open-circuit potential closer to that of iron but at the same time to ensure that the open-circuit potential is high enough that the base $\mathrm{Zn}-\mathrm{Ni}$ alloy still sacrificially protects iron. One of the limitations of this model lies in the success in obtaining consistent steady-state hydrogen permeation current densities. Under corroding conditions, it has been observed that the permeation current density keeps decreasing with time, due to a decrease in the corrosion current density, owing to the formation of oxide layers on the cathodic side. These difficulties in acquiring experimental data for mild steels can be overcome by using a large-surface-area electrode and by carrying out the experiments in acidic conditions where one would not expect passive layer formation. In a system that undergoes sacrificial corrosion like $\mathrm{Zn}$, or on other hard steels which do not form passive oxide layers or corrosion products, this model can be used to get a very good estimate of the hydrogen evolution and permeation parameters.

\section{Acknowledgment}

Financial Support by A. John Sedriks, the Office of Naval Research, under contract no. N00014-98-1-0053, is gratefully acknowledged.

Manuscript submitted September 4, 1997; revised manuscript received February 27, 1998.

The University of South Carolina assisted in meeting the publication costs of this article.

\section{LIST OF SYMBOLS}

$C_{i} \quad$ concentration of species $i, \mathrm{~mol} / \mathrm{cm}^{3}$

$E$ electrode potential, $\mathrm{V}$

$E_{\text {corr }}$ corrosion potential, V

$E_{i}^{\mathrm{o}} \quad$ equilibrium potential for the reaction i, V

$D$ diffusion coefficient, $\mathrm{cm}^{2} / \mathrm{s}$

$F \quad$ Faraday's constant, $94,487 \mathrm{C} / \mathrm{mol}$

f $F / R T, \mathrm{~V}^{-1}$ $i_{v} \quad$ exchange current density, $\mathrm{A} / \mathrm{cm}^{2}$ cathodic (discharge) current, $\mathrm{A} / \mathrm{cm}^{2}$ recombination current density, $\mathrm{A} / \mathrm{cm}^{2}$ permeation current density, $\mathrm{A} / \mathrm{cm}^{2}$

rate constant for the discharge reaction, $\mathrm{cm} / \mathrm{s}$

$k_{3}$ rate constant for the recombination reaction, $\mathrm{cm} / \mathrm{s}$ (or $\mathrm{mol} / \mathrm{cm}^{2} \mathrm{~s}$ )

$k_{3} \quad$ rate constant for absorption reaction, $\mathrm{mol} / \mathrm{cm}^{2} \mathrm{~s}$

$k_{4}$ rate constant for the reverse absorption reaction, $\mathrm{cm} / \mathrm{s}$

$k_{\mathrm{a}} \quad$ thickness dependent adsorption-absorption constant, $\mathrm{mol} / \mathrm{cm}^{2} \mathrm{~s}$

$L \quad$ thickness of the membrane, $\mathrm{cm}$

$N_{\mathrm{i}} \quad$ flux of a species i, $\mathrm{mol} / \mathrm{cm}^{2} \mathrm{~s}$

$p$ parameter determining the effective concentration for $i_{c}$

$q$ parameter determining the effective concentration for $j_{x}$

$R \quad$ universal gas constant, $8.314 \mathrm{~J} \mathrm{~kg}^{-1} \mathrm{~K}^{-1}$

$T$ temperature, $\mathrm{K}$

$x$ directional coordinate, $\mathrm{cm}$

$z_{\mathrm{i}} \quad$ charge number of species i

Greek

$\theta \quad$ adsorbed hydrogen coverage

$\eta \quad$ overpotential for the hydrogen evolution reaction (Eq. 8), V

$\eta_{\mathrm{a}} \quad$ applied overpotential $\left(E-E_{\text {corr }}\right), \mathrm{V}$

$\alpha \quad$ cathodic transfer coefficient

\section{REFERENCES}

1. D. H. Coleman, G. Zheng, B. N. Popov, and R. E. White, $J$. Electrochem. Soc., 143, 1871 (1996).

2. R.-H. Song and S. Pyun, J. Electrochem. Soc, 137, $1051(1990)$

3. M. Zamanzadeh, A. Allam, C. Kato, B. Ateya, and H. W. Pickering, J. Electrochem. Soc., 129, 284 (1982).

4. D. H. Coleman, Ph.D. Dissertation, University of South Carolina, Columbia, SC (1996).

5. M. A. V. Devanathan and Z. Stachurski, Proc. R. Soc., London, Ser. A, 270, 90 (1962).

6. J. McBreen, L. Nanis, and W. Beck, J. Electrochem. Soc., 113, 1218 (1966)

7. B. S. Chaudhari and T. P. Radhakrishnan, Surf. Technol., 22, 353 (1984).

8. S. K. Yen and H. C. Shih, J. Electrochem. Soc., 135, 1169 (1988).

9. R. N. Iyer, H. W. Pickering, and M. Zamanzadeh, J. Electrochem. Soc., 136, 2463 (1989).

10. P. Manolatos, M. Jerome, C. Duret-Thual, and J. Le Coze, Corros. Sci., 37, 1773 (1995)

11. J. O'M Bockris, J. McBreen, and L. Nanis, J. Electrochem. Soc., 112, 1025 (1965)

12. B. Lustman, Trans. Electrochem. Soc., 84, 363 (1943)

13. S. Swathirajan, J. Electrochem. Soc., 133, 671 (1986).

14. B. N. Popov, M. Ramasubramanian, S. N. Popova, R. E. White, and K-M. Yin, J. Chem. Soc., Faraday Trans. 92, 4021 (1996)

15. B. G. Pound, in Modern Aspects of Electrochemistry, No. 25, J. O'M Bockris, B. E. Conway, and R. E. White, Editors, p. 63, Plenum Press, New York (1993). 